\title{
st \\ Uma discussão sobre a unidade da ciência: Neurath e a utopia da ciência unificada
}

\author{
Ivan FerReira DA Cunha
}

\begin{abstract}
茴
RESUMO

Neste artigo apresentamos as propostas de Otto Neurath para o problema da unidade da ciência. Conhecido integrante do Círculo de Viena, Neurath defende que a ciência deve ser unificada por meio da chamada concepção de mundo científica (wissenschaftliche Weltauffassung), uma orientação ou atitude em relação ao mundo e aos problemas que é característica da ciência. Neste artigo apresentamos o caráter social dos projetos de Neurath, como o da Enciclopédia Internacional da Ciência Unificada. Contrastamos a proposta de Neurath com a crítica pós-modernista da abordagem contextualizada dos estudos sobre a ciência (science studies). Essa crítica parte de estudos de comunidades científicas e, em geral, apresenta a conclusão de que não há um fator que unifique a ciência. O termo "ciência" denotaria apenas uma coleção de atividades sem características relevantes em comum. A comparação feita mostra que a posição de Neurath é compatível com a abordagem contextualizada, apesar de defender a unidade da ciência. Por fim, avaliamos o aspecto político da proposta de Neurath diante da crítica pós-moderna e notamos que as ideias do Círculo de Viena e da Enciclopédia podem ser valiosas nos dias de hoje.
\end{abstract}

Palavras-chave • Unidade da ciência. Neurath. Círculo de Viena. Abordagem contextualizada. Utopia. Ciência unificada.

\section{InTroduçÃo: Neurath E O PRoblema dA UNIDADE DA GIÊNGIA}

Este texto tem como objetivo apresentar as propostas de Otto Neurath para o problema da unidade da ciência. Tais propostas, pouco discutidas atualmente, em particular no Brasil, relacionam-se aos projetos sociais em que Neurath trabalhou, bem como às discussões do Círculo de Viena, grupo do qual ele fazia parte. Assim, nossa apresentação conterá relatos breves de tais projetos e discussões.

Entende-se comumente que a ciência compreende variadas atividades, produções e instituições, bem como conhecimentos, métodos e pontos de vista. 0 problema da unidade da ciência pode ser instanciado na questão sobre como reunir tal multiplicidade em um único conceito, o de ciência. Dependendo da maneira como se lida com o problema da unidade da ciência, outros problemas podem surgir: um deles é o problema da demarcação, que diz respeito à distinção entre ciência e não ciência. Outro 
problema é o da unidade ontológica do mundo com o qual a ciência lida, isto é, se os fenômenos trabalhados pela ciência são de uma natureza única. No presente artigo, procuraremos evitar os dois problemas.

Podemos inicialmente considerar três tipos de respostas mais comuns ao problema da unidade da ciência. O primeiro é que a ciência é aquilo que é produzido por certo método, o método científico. O segundo é que a ciência é um corpo de conhecimentos que possui certas características, como o fato de ter origem na experiência, ou o encadeamento lógico de suas partes, ou a propriedade de explicar o mundo. O terceiro é aquele que defende que a ciência é uma coleção de atividades com uma origem histórica comum, a saber, a filosofia natural dos séculos XVI e xvII, que acabou por diversificar-se em atividades que não guardam semelhanças significativas entre si.

As duas primeiras abordagens apresentam dificuldades sérias, geralmente apontadas pelos defensores da terceira, envolvendo o fato de que a observação da atividade científica leva-nos a crer que não há uma unidade de método e nem de conteúdos. Diferentes métodos podem ser notados em cada uma das áreas da ciência, e até mesmo dentro de uma mesma área. Da mesma forma, o corpo de conhecimentos dos diferentes ramos científicos pode ser sistematizado e ter a sua relação com a experiência apresentada, mas não parece ser possível sistematizar toda a ciência de maneira uniforme, e nem encontrar um único modo de analisar-se a relação entre observação e teoria. Propostas a respeito de o que seria o método científico ou a respeito de como unir todos os conteúdos da ciência acabariam restringindo demais o escopo do que se entende por ciência. As dificuldades que a terceira concepção apresenta, em nosso ponto de vista, é que ela aparentemente dá apenas uma resposta provisória ao problema da unidade da ciência, a de que é ciência aquilo que as comunidades científicas fazem, dando a impressão de que não estamos procurando corretamente o fator de unidade.

Há ainda uma resposta que é proveniente dos autores pragmatistas americanos, de que a ciência é aquilo que é produzido por determinada maneira de pensar. Encontramos tal concepção, por exemplo, na teoria da investigação de Dewey (cf. 2008 [1938]). Basicamente os pragmatistas defendem que há uma série de etapas pelas quais o pensamento pode avançar de modo a garantir asserções, isto é, de modo a obter conhecimento seguro. Trata-se de um método tomado de maneira bastante ampla, concebido como uma maneira de pensar. Isso é posto pelos pragmatistas de forma fisiológica, como uma característica da biologia humana, algo que se desenvolveu em nossa espécie ao longo da evolução, e que trouxe como resultado aquilo que chamamos de ciência. O pensamento típico da ciência é, dessa forma, uma característica da espécie humana, e a ciência é vista como um instrumento para a nossa sobrevivência no mundo. Essa concepção se distingue de todas as outras justamente por adotar um ponto de partida fisiológico e psicológico. 
Neste artigo, vamos apresentar outra abordagem, a de que a ciência é uma maneira de ver, ou conceber, o mundo. Essa abordagem foi trabalhada no século xx pelo grupo de pensadores conhecido como Círculo de Viena. No manifesto de tal grupo, publicado em 1929, conhecido como A concepção científica do mundo (cf. Hahn, Neurath \& Carnap, 1979 [1929]), é apresentada a concepção científica de mundo (wissenschaftliche Weltauffassung), que se liga a uma atitude caracterizada pelo princípio de que não existem "enigmas indecifráveis", "distâncias escuras" ou "profundezas insondáveis", tal como é defendido por sistemas teológicos e metafísicos. A atitude de que não há enigmas deve ser incentivada e reforçada entre todas as pessoas, de modo a melhorar os sistemas educacionais e a qualidade de vida em geral, já que se trata de uma defesa da capacidade humana de resolver os problemas que o mundo apresenta, sem recorrer a nenhuma forma de pensamento mágico ou de fé, e sem propor que nos resignemos diante das dificuldades (cf. Hahn, Neurath \& Carnap, 1979 [1929], p. 86-8).

A atitude científica é a de estabelecer oposição àquilo que poderíamos chamar de atitude mística em relação ao mundo: a atitude de considerar que há mistérios insolúveis no mundo. Deve ficar claro, porém, que não é essa oposição que determina o que é ciência, já que há produções que não são nem místicas nem científicas. O que caracteriza a unidade da ciência no Manifesto é a concepção do mundo como universalmente cognoscível, sem considerar conhecimento as vivências místicas as quais não poderiam ser apreendidas por conceitos de estados de coisas e expressas em uma linguagem compreensível (cf. Hahn, Neurath \& Carnap, 1979 [1929], p. 88).

No Manifesto, fala-se também do "corpo dos conhecimentos produzidos pela concepção científica do mundo". O Círculo de Viena é caracterizado por lidar com tal corpo de conhecimentos utilizando ferramentas da lógica simbólica, que permitiriam compreender melhor como se conectam os conceitos da ciência. Tal proposta foi desenvolvida por Rudolf Carnap, o integrante mais conhecido do Círculo de Viena, na forma de um sistema lógico em que todos os objetos (tanto conceitos quanto eventos) da ciência podem ser relacionados a objetos presentes na experiência elementar de um sujeito. Tal sistema lógico é composto por uma sintaxe que permitiria formular todos os enunciados da ciência, e deixaria de fora os enunciados metafísicos, proporcionando uma resposta também para o problema da demarcação. ${ }^{1}$

A crítica feita à metafísica é que seus objetivos envolvem principalmente a expressão de sentimentos, produzindo enunciados que não satisfazem o critério proposto por Carnap. O objetivo de expressar sentimentos é importante, mas a metafísica não é o meio adequado para isso. No Manifesto, defende-se que tal tarefa deva ser realizada

1 Carnap apresentou essa proposta no livro conhecido como Aufbau (2003 [1928]). Posteriormente, Carnap deixou de exigir referência à experiência elementar de um sujeito, tomando como primitivos do sistema os objetos físicos, localizáveis no espaço e no tempo. Tal mudança, já sugerida no Aufbau, foi apresentada em Carnap (1995 [1931]). 
pela arte, e não por tentativas de teorização que pretendem gerar conhecimento (cf. Hahn, Neurath \& Carnap, 1979 [1929], p. 88). Alguns anos mais tarde, Carnap diria que os metafísicos são músicos sem habilidade musical que, por não dominarem nenhum instrumento, voltam-se para pesquisas pretensamente teóricas (Carnap, 1931, p. $238-4,1)^{2}$

Essa proposta de Carnap, que é uma das mais influentes do Círculo de Viena, enquadra-se naquilo que descrevemos no início deste texto como o segundo tipo de respostas tradicionais ao problema da unidade da ciência, a saber, a de que a ciência é um corpo de conhecimentos com certas propriedades. No entanto, notamos que, no Manifesto, propõe-se que o que unifica a ciência é uma atitude, uma concepção de mundo. Devemos, assim, observar especificamente a obra de Otto Neurath para compreender melhor essa outra forma de abordar o problema da unidade da ciência. A obra de Neurath está composta em grande parte por trabalhos políticos e sociológicos, e devemos entender seu posicionamento científico nessas áreas para construir uma imagem mais adequada da concepção científica do mundo.

É preciso ressaltar, contudo, que as propostas do Círculo de Viena não formam um sistema completamente uniforme. Procuraremos aqui compreender a articulação das propostas de Neurath, da ciência como uma atitude, em relação às propostas de Carnap, da ciência como um corpo de conhecimentos, mas deve ficar claro que sempre haverá algumas diferenças, o que é desejável de um ponto de vista mais amplo, que pode ser tomado como a proposta do Círculo de Viena (cf. Creath, 1996; Liston, 2009).

\section{Os projetos sogiais de Neurath}

Neurath não era um acadêmico tradicional; com formação universitária em sociologia e economia, sua ocupação principal não era a de professor universitário. $O$ foco de seu trabalho era prático, político, e isso aparece em sua obra acadêmica (cf. Uebel, 1991; Cartwright et al., 1996; Nemeth, Schmitz \& Uebel, 2007; Symons, Pombo \& Torres, 2011). Essa característica ficou evidente durante a Primeira Guerra Mundial, quando Neurath servia no exército austro-húngaro. Diante do que acontecia nas cidades ocupadas, ele procurou observar e registrar dados sobre a situação econômica de racionamento, com o objetivo de aplicar nos tempos de paz aquilo que se aprende durante essas épocas difíceis. Após a guerra, no contexto da reconstrução, Neurath foi encarregado do planejamento econômico e social do estado alemão da Bavária. Seu trabalho era atender às demandas dos diferentes setores sociais - tanto de empresários, industriais e comerciantes, quanto de trabalhadores, mineradores e camponeses - para re2 Essa comparação de Carnap era um ataque a Heidegger (cf. Friedman, 2000). 
alizar uma melhor distribuição da força de trabalho e dos bens disponíveis. Neurath conseguiu realizar bem tal tarefa durante alguns meses, mas seu trabalho foi interrompido por uma revolução comunista que dissolveu o governo do qual ele fazia parte. Os revolucionários, vendo o sucesso do planejamento feito por Neurath, quiseram que ele adaptasse seus projetos à nova ordem social. Porém, quando a revolução foi violentamente reprimida, Neurath foi considerado um traidor e deportado de volta à Áustria (cf. Neurath \& Cohen, 1973, p. 7-29; Cartwright et al., 1996, p. 7-63).

A partir de projetos como esses, Neurath desenvolveu a visão de que o cientista social trabalha para criar utopias, modelos abstratos que apresentam possibilidades para o funcionamento de um agrupamento de pessoas. Utopias propõem projetos de habitação e de urbanização, políticas de distribuição de riquezas, padrões de estilo de vida e sistemas educacionais, entre outras reformas. A partir disso, o trabalho dos políticos é aplicar tais utopias, da mesma forma que os engenheiros e tecnólogos aplicam modelos da física a situações práticas. A ciência social, dessa forma, propõe alternativas às situações vividas pelas pessoas (cf. Nemeth, 1991 [1982], 2007; Nemeth, Schmitz \& Uebel, 2007, p. 3-12).

Devemos destacar que, para Neurath, o cientista social cria as utopias a partir das situações vividas pelas pessoas. Além disso, no momento da aplicação, as pessoas envolvidas devem ter o máximo de informação acerca das possibilidades de mudança. Dessa forma, não se trata de uma visão tecnocrata da engenharia social, em que governantes que detêm o conhecimento aplicam certos arranjos tidos como ideais, baseados em teorias consideradas corretas, em uma sociedade que é passiva no processo. A ciência social deve garantir às pessoas a liberdade de mudar suas condições de vida; e tal liberdade vem da informação e da participação na produção do conhecimento.

Nenhuma produção humana, seja filosófica, científica, artística ou política, pode ser considerada universalmente boa, correta ou válida. Assim, para Neurath, uma solução proposta pela ciência social não pode ter a pretensão de ser infalível e final. Alguns problemas sempre restarão, assim como surgirão novos desafios. A engenharia social tecnocrata é uma forma do que Neurath chama de pseudorracionalismo, a suposição de que a razão sozinha e bem exercitada de uma elite educada vai ser capaz de fornecer soluções absolutamente corretas que funcionam em todos os casos para todas as pessoas (cf. Neurath, $197^{3}$ [1921]; Nemeth, 1991 [1982], p. 288-90). A ciência é o caminho para melhorar a vida humana, mas isso deve ser feito em um processo de discussão com a comunidade envolvida, de maneira falível, recebendo contrapropostas e analisando alternativas.

Neurath teve uma oportunidade de aplicar seus projetos na Bavária em 1919, mas não pôde continuar seu trabalho devido à instabilidade política. Porém, durante a década de 1920, Neurath trabalhou em projetos de habitação e urbanização da prefeitura 
de Viena. Tais projetos visavam transformar os cortiços e favelas, que começaram a formar-se depois da guerra, nas chamadas habitações comunais - blocos de edifícios, no centro dos quais há uma ampla área comum com lavanderias, playgrounds, creches, hortas e outros espaços de convivência. Um problema da época, que serve como exemplo, era que todos os adultos de uma família precisavam trabalhar fora e não tinham com quem deixar as crianças fora do horário escolar, algo que foi resolvido com o playground no centro do condomínio - longe das ruas que se tornavam cada vez mais movimentadas e facilmente supervisionadas por algum vizinho que estivesse disponível (cf. Neurath, 1996, p. 20-3). ${ }^{3}$ Na década de 194.0, Neurath trabalhou no município de Bilston, na Inglaterra, em um projeto semelhante àquele desenvolvido em Viena. O trabalho de Neurath diferenciou-se de outros programas de mesma finalidade naquele país por ter sido amplamente democrático, levando em conta o que cada pessoa tinha como ideais de moradia, sem impor formatos predeterminados de apartamentos ou de condomínios (cf. Cohen \& Neurath, 1973, p. 75-9).

Neurath via esses projetos como benefícios trazidos pelo desenvolvimento e expansão da concepção científica do mundo. A proposta é utilizar a atitude científica para analisar as reivindicações das pessoas, ao invés de tomar como necessários e infalíveis certos modelos sobre o que é viver bem ou sobre como as riquezas devem ser distribuídas. Se o objetivo é melhorar o bem-estar das pessoas que recebem os produtos da ciência, esse deve ser o referencial adotado - e não a perfeição do modelo escolhido. Essa é uma visão bastante humanista da ciência e da tecnologia.

Diante disso, quando pensamos que os modelos sociais devem ser amplamente conhecidos pelas comunidades envolvidas nos projetos, temos como condição que a comunicação e a educação devem ser trabalhadas. Neurath desenvolveu dois projetos para facilitar a comunicação de conceitos e teorias científicas para um público mais amplo. O primeiro é o ISOTYPE, uma linguagem visual para informar pessoas que não sabem ler, ou que não conhecem o linguajar técnico de certas áreas, sobre estatísticas e outras informações sociais, políticas e econômicas que influenciam a vida delas (cf. Cohen \& Neurath, 1973, cap. 7). O segundo projeto ficou conhecido como fisicalismo, e é o projeto de elaborar os enunciados da ciência em termos de objetos à nossa volta, das coisas da vida cotidiana. Tal projeto é frequentemente mal interpretado como se fosse um requisito de reduzir todas as ciências à física. Embora algumas formulações feitas pelo Círculo de Viena permitam tal interpretação errônea, a compreensão dos projetos sociais e econômicos de Neurath permite entender que o fisicalismo tem um objetivo educacional de disseminação do conhecimento científico e, portanto, de promover melhorias nas sociedades e na vida das pessoas.

3 É possível encontrar as habitações comunais da época de Neurath e também das décadas posteriores, feitas no mesmo estilo, em muitos bairros de Viena, e mesmo na região central da cidade. 


\section{A utopia dA Giência UNIFICADA}

Uma das utopias elaboradas por Neurath é a chamada ciência unificada, a proposta de comunicação e cooperação entre os cientistas das mais diversas áreas, e também com a participação das pessoas que adotam a atitude científica e que consomem os produtos da ciência. Tal projeto, como posto no Manifesto, era o grande objetivo do Círculo de Viena (cf. Hahn, Neurath \& Carnap, 1979 [1929], p. 86-7). Isso seria facilitado pelo fisicalismo, a ferramenta linguística para formular os enunciados de todas as áreas da ciência em termos que podem ser traduzidos para todos os idiomas e dialetos, dos mais variados lugares e níveis de instrução, naquilo que Neurath chamou de "jargão universal". A lógica formal serviria, nesse contexto, para aperfeiçoar esse jargão, tornando-o tão livre de ambiguidades quanto possível. Notemos que Neurath não tinha a pretensão, que ele considerava pseudorracionalista, de alcançar uma linguagem completamente pura; mas apenas estabelecer um esforço constante para refinar a linguagem que obtivermos (cf. Neurath, 1983 [1937], p. 172-4).

Podemos entender o conhecido projeto de Carnap da criação de linguagens artificiais nesse contexto de elaboração de ferramentas para melhorar o jargão universal. Ao longo dos anos 1930, lidando com a noção de "linguagem das coisas" ,4 Carnap propôs que cada ramo específico da ciência tenha seu próprio linguajar técnico, com suas leis e esferas ontológicas. Mas deve ser possível relacionar cada um desses dialetos à linguagem das coisas, criando as condições para o jargão universal de que Neurath falava, sem precisar envolver as leis científicas (cf. Neurath, 1983 [1937], p. 176).

O projeto de elaborar uma linguagem das coisas, à qual os jargões técnicos das diversas áreas da ciência podem ser relacionados, deveria ser desenvolvido em direção à ética e à arte. Isso permitiria mais avanços e abriria mais campos de estudo nessas áreas, ampliando ainda mais os benefícios da disseminação da atitude científica (cf. Neurath, 1983 [1941], p. 222-4; Neurath, 1983 [1937], p. 175-6). Devemos notar, assim, que Neurath já defendia naquela época a comunicação intercultural, que seria facilitada quando os produtos científicos, artísticos e filosóficos fossem apresentados na maneira como se relacionam com os objetos cotidianos em uma linguagem articulada de maneira lógica.

Além disso, é possível perceber que o fisicalismo não é o fator determinante da unidade da ciência: outros tipos de produção podem ser formulados em tal linguagem. Como dissemos, a linguagem fisicalista é uma ferramenta para auxiliar na unificação da ciência por meio da concepção científica de mundo. A ciência unificada, assim, não

4. Em inglês, thing-language. O termo foi adotado devido aos mal-entendidos envolvendo a expressão "linguagem fisicalista" (cf. Carnap, 1936, p. 466). 
é imposta pela construção de uma linguagem básica. Da mesma forma que nos outros projetos de Neurath, a ciência unificada previa a ampla participação de todos os envolvidos, formando uma união das pessoas que compartilham uma concepção de mundo, em sentido amplo. E tal união é levada adiante por meio da coordenação, ou orquestração, das diferentes áreas da ciência (cf. Cat, Cartwright \& Chang, 1996, p. 362-9).

Um aspecto importante da proposta de Neurath para a união da concepção científica do mundo é o pluralismo. A visão de mundo de cada uma das pessoas e dos grupos de pessoas não é, e não deve ser, idêntica. Neurath diz que a própria ciência é constituída desse modo em cada um dos seus ramos específicos. Os enunciados observacionais, por exemplo, são concebidos por Neurath como um complexo de conceitos que não são simplesmente absorvidos pelos órgãos dos sentidos. Há elementos sensoriais e há elementos culturais, históricos e sociais nos enunciados observacionais, que, portanto, não são simples e nem primitivos, no sentido filosófico comum; e cada comunidade científica, de cada ramo da ciência, chega a convenções a respeito do que é observacional, assim como a respeito do que é aceitável. E nenhuma dessas convenções é definitiva ou imposta às pessoas; elas são desenvolvidas de maneira comunitária, em uma cooperação entre as pessoas interessadas. O pluralismo de Neurath mostra que não se trata da proposta de uma superciência para legislar sobre as outras, nem de uma visão metafísica do mundo que compreende tudo, mas da construção de conexões entre as ciências, mantendo a especificidade de cada área (cf. Neurath, 1983 [1937], p. 172-4). A ciência vai sendo construída e alterada enquanto vai acontecendo. A ciência, para Neurath, assim como todos os aspectos da vida humana, está constantemente, por assim dizer, em obras, no processo de fazer-se. 5

Três imagens propostas por Neurath ajudam a compreender o caráter plural da ciência unificada, além da noção de que a ciência está sempre em processo de ser feita, de ser reconstruída, e de que uma reconstrução completa nunca é possível.

(a) A ilustração do barco foi apresentada por Neurath em vários textos, mas a versão mais famosa é aquela em que ele diz que "somos como marinheiros que precisam reconstruir seu barco em mar aberto, sem jamais poder desmontá-lo em doca seca, e reconstruí-lo ali com os melhores componentes" (Neurath, 1983 [1932/1933], p. 92). Essa ilustração mostra a oposição que Neurath estabeleceu à estratégia filosófica de elaborar um sistema, isto é, a tentativa de construir o conhecimento como um todo uniforme. Tais estratégias geralmente procuram uma base sólida e livre de dúvidas para, a partir daí, justificar o conhecimento utilizando algum método uniforme. Neurath está opondo-se, dessa forma, a sistemas filosóficos como o de Descartes e o de Kant, que

5 A expressão em língua inglesa utilizada por Neurath é "in the making", que pode ser traduzida como "no fazer" ou “ao fazer”, representando a ideia de algo que está em processo de ser feito (Neurath, 1983 [1941], p. 214). 
não notavam que é impossível sair da nossa condição de navegantes em mar aberto para encontrar uma doca seca. Qualquer base sólida que encontrarmos será uma ilusão, pois não podemos simplesmente sair de nossos contextos sociais, assim como não podemos deixar totalmente de lado nosso conhecimento prévio. Neurath compara o barco - e, consequentemente, a ciência - à própria vida, já que não podemos "sair" e recomeçar do zero (cf. Neurath, 1983 [1936], p. 150).

A pretensão de que é possível elaborar um sistema que compreenda toda a construção humana, seja artística, seja filosófica, seja científica, é uma forma de pseudorracionalismo. É uma tentativa de elaborar uma resposta segura e final, absolutamente correta, e válida em todos os contextos; devemos estar cientes de que não podemos aportar em doca seca e construir o sistema filosófico perfeito, o melhor que podemos fazer é seguir navegando com o que temos à nossa disposição.

(b) Neurath nos pede para imaginar um grupo de artesãos, como carpinteiros, que está construindo algumas casas. Eles possuem um gaveteiro cheio de ferramentas, mas apenas algumas de tais ferramentas estão bem organizadas, e os artesãos sabem usar apenas uma parte delas. Novos instrumentos são adicionados ao gaveteiro o tempo todo, e algumas ferramentas são modificadas por estranhos. Os artesãos têm que aprender a usar as velhas ferramentas de um jeito até então desconhecido, e, além disso, os planos e projetos das construções que eles estão fazendo mudam o tempo todo. Neurath diz que "isso se parece até certo ponto com a situação dos nossos cientistas" (Neurath, 1983 [1941] , p. 215). Ou seja, para ele, fazer ciência envolve o uso de certas ferramentas que, muitas vezes, não conhecemos adequadamente; novos materiais aparecem de maneira inesperada, e os objetivos para o uso das ferramentas mudam com frequência. E se vamos elaborar um retrato da ciência, tentar compreender o que é essa atividade, temos, também, que lidar com essa situação. Neurath diz que "o jargão universal sempre estará em processo de produção, assim como nossa vida e nossas ciências" (Neurath, 1983 [1941], p. 214).

Sendo assim, os enunciados de observações científicas não são propriamente atômicos no sentido de serem indivisíveis e isoláveis, mas eles se apresentam em um corpo de enunciados, em meio a porções de teoria, da mesma forma que as ferramentas no gaveteiro, que podem ser agrupadas das mais diversas maneiras. "Consequentemente, nenhum 'sistema único do mundo' permanece (...), mas apenas feixes de corpos de enunciados que mais ou menos se encaixam no nosso padrão científico" (1983 [1941], p. 215).

Supor que nossas ferramentas de raciocínio são completas e perfeitas, ou mesmo que um dia chegaremos a ter ferramentas com tais características é algo que se enquadra naquilo que Neurath chama de pseudorracionalismo. Mesmo que a nossa lógica ou a nossa física, por exemplo, pareça ideal para nossos objetivos, devemos continuar 
sempre pesquisando e tentando melhorar: pode ser que nosso objetivo mude no futuro, ou simplesmente que encontremos algo totalmente diferente que muda o nosso modo de pensar.

(c) A ilustração do mosaico apareceu na Enciclopédia Internacional da Ciência Unificada (International Encyclopedia of Unified Science) (Neurath, Carnap \& Morris, 1955), um projeto apresentado ao longo dos anos 3o, naquilo que Neurath chamou de "movimento pela ciência unificada, e desenvolvido no final daquela década e ao longo das três décadas posteriores. O objetivo de tal projeto era pôr em prática a utopia da ciência unificada em que todas as pessoas que compartilham a concepção científica do mundo unem-se e comunicam-se sobre suas produções e suas visões da ciência. Tal cooperação criaria uma obra, a própria Enciclopédia, que serviria como uma fonte de aprendizado e referência sobre a maneira científica de ver o mundo e de resolver problemas. A ciência seria mostrada na Enciclopédia como um mosaico, uma coleção de peças irregulares e diferentes umas das outras, mas que, devidamente organizada ou orquestrada (cf. Neurath, 1983 [194,6]), gera uma imagem quando vista a partir de certa distância. Isso ilustra a pluralidade de visões científicas, a multiplicidade de maneiras como a ciência pode ser compreendida e a variedade de respostas que a ciência pode dar aos problemas do mundo.

Neurath diz que várias enciclopédias são possíveis, diante de toda essa pluralidade de visões que a concepção científica do mundo oferece, de modo que a obra que ele estava propondo seria uma enciclopédia, e não a enciclopédia. Haveria, assim, certa uniformidade nas maneiras de pensar, resultado do próprio debate científico. Mas isso não deveria dar a impressão de que só há uma maneira de conceber o mundo, ou de que seria possível elaborar o sistema dos saberes humanos (cf. Neurath, 1983 [1936], p. 157).

A Enciclopédia começou a ser publicada no final dos anos 1930, quando os integrantes do Círculo de Viena já estavam exilados. Com a Segunda Guerra Mundial, o projeto foi atrasado, teve corte de verbas, mas continuou. E mesmo com a morte de Neurath, no final de 1945 , os outros editores, Carnap e o pragmatista americano Charles Morris continuaram com o projeto. Ao todo foram publicados dezenove números e uma bibliografia, organizados em dois volumes intitulados Foundations of the unity of science, que tiveram sua forma final publicada apenas em $197^{\circ}$.

O pseudorracionalismo aparece em relação ao mosaico na ilusão de que um dia a ciência chegará a produzir uma visão unívoca do mundo, com todas as suas partes em harmonia perfeita umas com as outras, em um sistema consistente de todos os saberes humanos. A concepção da ciência unificada em um mosaico opõe-se a essa noção de sistema. 
Até aqui fizemos uma apresentação das propostas de Neurath em direção ao problema da unidade da ciência. Nas próximas duas seções, indicaremos brevemente pontos de contato de tais propostas com outras: primeiro, com autores contemporâneos de Neurath, com quem ele discutiu; e depois, com o tratamento dado mais recentemente ao problema da unidade da ciência.

\section{As oposições de Neurath a Carnap e Popper}

Ao estudar as propostas de Neurath, é possível considerar que ele estava estabelecendo uma oposição à filosofia da ciência de Carnap, já que notamos na obra de tal autor uma preocupação em elaborar um sistema lógico para a ciência, chegando a propor um critério de demarcação que determina que não seja conhecimento genuíno aquilo que não puder ser formulado no sistema lógico. Neurath se opunha àquilo que pode ser caracterizado como uma visão popular da filosofia do Círculo de Viena (cf. Cat, Cartwright \& Chang, 1996, p. 347).

No entanto, a lógica da ciência proposta por Carnap tem como primitivos os objetos físicos, de modo que todo o sistema deve ser construído em função dos objetos materiais, compreendidos formalmente em um sistema de coordenadas espaço-temporais. Assim sendo, o trabalho lógico de Carnap, na forma que tal trabalho adquiriu em meados dos anos 1930, deve ser visto como a elaboração de ferramentas para aperfeiçoar a proposta fisicalista de conceber toda a ciência em conexão com uma linguagem de objetos físicos, aquilo que Carnap depois chamaria de "linguagem das coisas" (cf. Carnap, 2002 [1934], p. 320-2; 1936, p. 466). Isso facilitaria a divulgação da ciência entre pessoas de diferentes áreas de instrução em variados graus, bem como de diferentes culturas.

É importante ressaltar também que as propostas de Carnap são guiadas pelo princípio de tolerância linguística, que diz basicamente que não há um sistema lógico que seja correto, mas que diversos sistemas são possíveis para diferentes fins. O filósofo da ciência não deve estabelecer proibições, segundo tal princípio, sendo tolerante em relação a formas de expressão, mas deve chegar a convenções a respeito de como compreender de maneira lógica e filosófica a linguagem, o conhecimento e a ciência (cf. Carnap, 2002 [1934], p. 51-2; Cunha, 2010; Ricketts, 2007).

Em seu primeiro grande livro, o Aufbau, como mencionamos, Carnap propôs um sistema construtivo que mostrava de que maneira era possível construir logicamente todos os domínios de objetos e eventos de que trata a ciência em termos de vivências elementares de um sujeito (cf. Carnap, 2003 [1928], p. 5-10, 98-121). Mesmo tal ela- 
boração, que viria a ser alterada depois com a adoção completa do fisicalismo, não pode ser vista como um dos alvos da crítica de Neurath ao pseudorracionalismo. Uma ilustração apresentada por Carnap no Aufbau assemelha-se bastante ao que ele formulou depois como o princípio de tolerância, e indica como tal sistema de construção se encaixa na utopia de Neurath. ${ }^{6}$ Trata-se da ilustração dos mapas ferroviários (cf. Carnap, 2003 [1928], p. 25-7). Carnap sugere que tomemos um mapa de alguma malha ferroviária e notemos que dificilmente tal mapa trará todas as características da malha. Geralmente os mapas de linhas de trem ou metrô não indicam todas as curvas feitas pelos trilhos e nem são fiéis às distâncias entre as estações. Apenas a posição de cada estação em relação às outras estações da linha, e as possibilidades de conexão com outras linhas em cada uma das estações são representadas, o que é em geral suficiente para que os usuários se locomovam. Mas podemos encontrar outros mapas que representem outros elementos da malha ferroviária, como a distância entre as estações, ou ainda as curvas, subidas e descidas dos trilhos.

Carnap usa os mapas ferroviários como metáfora do processo de produzir e utilizar sistemas lógicos de conhecimento. Um sistema não é feito para capturar todas as relações lógicas possíveis entre os objetos da ciência, mas apenas para retratar algum aspecto, de acordo com certo objetivo. A construção feita no Aufbau indica como compreender as relações dos objetos dos diferentes ramos da ciência com a experiência pessoal de uma pessoa. Depois, Carnap (1995 [1931]) propôs que a base do sistema fosse composta de objetos físicos. Com efeito, o Aufbau já previa essa possibilidade (cf. Carnap, 2003 [1928], p. 94-6). As relações encontradas entre tais objetos caracterizam o primeiro passo na construção do jargão universal, a linguagem fisicalista a qual, como vimos, Neurath apresenta como algo em processo de fazer-se. Não se trata, portanto, de algo acabado, mas de algo que está sempre em processo de reconstrução. É um retrato que mostra certos aspectos da ciência a partir de certo ponto de vista e não é, portanto, o sistema almejado pelos pseudorracionalistas.

Já a proposta de Karl Popper, conhecida como falseacionismo metodológico, enfrenta críticas diretas por parte de Neurath. Para Popper, a ciência pode ser caracterizada por um método de formulação de hipóteses, dedução de consequências das hipóteses e teste de tais consequências. É científico, segundo tal caracterização, um enunciado que seja capaz de ser submetido a teste, podendo ser falseado. A proposta de Popper desenvolve-se a partir disso como uma análise lógica de um método científico ideal que visa garantir a falseabilidade da ciência. Assim, ele propõe regras metodológicas, como a de evitar hipóteses ad hoc e a de garantir que haja hipóteses concorrentes para apoiar

6 Ressaltemos também que, na Enciclopédia, Neurath cita o Aufbau como exemplo de produção gerada pela atitude científica em relação ao mundo (cf. Neurath, 1955 [1938], p. 12-3). 
os testes cruciais (cf. Popper, 2003 [1934], p. 27-50). O objetivo do procedimento científico, para Popper, "não é o de salvar a vida de sistemas insustentáveis, mas, pelo contrário, o de selecionar o que se revele, comparativamente, o melhor, expondo-os todos à mais violenta luta pela sobrevivência" (Popper, 2003 [1934], p. 44). A série de testes pode parar devido a uma decisão convencional, mas o fato de uma hipótese ter resistido a um grande número de testes não nos permite caracterizá-la como "verdadeira", apenas como "corroborada"; uma hipótese que não sobreviveu aos testes, por outro lado, pode ser considerada "falsa" (cf. Popper, 2003 [1934], cap. 10).

O objetivo de Popper, contudo, não é o de descrever a atividade científica, mas apenas o de estabelecer um critério de cientificidade e de julgamento lógico filosófico para as hipóteses (cf. Popper, 2003 [1934], p. 31). E podemos identificar aí o foco da crítica de Neurath, que assume uma postura naturalista. Neurath ataca a noção de que há um critério universal para julgar a qualidade e a cientificidade de todas as hipóteses, caracterizando como pseudorracionalista a tentativa popperiana de "objetivar um único e distinto sistema de enunciados como o padrão ou paradigma de todas as ciências factuais" (Neurath, 1983 [1935], p. 121). A proposta de Popper, assim, teria resquícios de concepções metafísicas tradicionais, e acabaria incorrendo em uma forma de absolutismo (cf. Neurath, 1983 [1935], p. 128-31).

A ciência, para Neurath, é uma atividade largamente plural, tendo variados métodos para avaliar hipóteses, dependendo da área, da comunidade envolvida, e dos objetivos da pesquisa naquele momento. Esse é um aspecto importante da ciência que, de acordo com Neurath, deve ser refletido pela filosofia da ciência, de modo a retratar a importância social de tal empreendimento. O pseudorracionalismo que Neurath vê na proposta de Popper é aquele que supõe que todo o conhecimento humano é construído a partir dos mesmos critérios de racionalidade, tendo os mesmos objetivos, ou seja, a partir de pessoas que pensam da mesma maneira - e isso se reflete na maneira de justificar o conhecimento (cf. Neurath, 1983 [1935], p. 123-8). Neurath insiste que notemos que há diversidade dentro da própria concepção científica do mundo. Várias pessoas podem pensar de maneira diferente umas das outras, mas ainda assim podem todas elas estar pensando de maneira científica. A estratégia de procurar o método único para a construção do sistema da ciência não é uma boa ideia, nem como uma aproximação, nem como uma consequência do princípio de que há o mundo real em direção ao qual a ciência progride. Tais propostas são reflexos da atitude metafísica oposta à ciência.

Um aspecto da proposta de Neurath que pode ser visto como uma crítica tanto a Carnap quanto a Popper é a de que não podemos considerar que nossas convenções são ilimitadas, seja a convenção carnapiana de determinar de que maneira o sistema lógico será construído, seja a convenção de Popper a respeito de quando parar a série de 
testes. A ciência está sempre em processo de fazer-se, de reconstruir-se, assim como a filosofia da ciência, de modo que não é possível que tenhamos à mão o tempo todo as melhores ferramentas para a nossa análise - incluindo a capacidade de chegar à melhor convenção possível. Isso não afeta muito diretamente a construção de sistemas lógicos, mas podemos imaginar uma situação em que um lógico percebe que seria melhor para certa teoria científica se outra matemática fosse adotada; ele pode sugerir tal caminho aos cientistas, mas eles não mudarão sua prática a não ser que um problema importante presente na prática deles seja resolvido com a mudança, sem perdas significativas. Assim, uma convenção que funciona melhor em um sistema lógico pode não ser a mais interessante na ciência. No caso da proposta de Popper, a historiografia da ciência que se desenvolveu alguns anos depois mostrou que os cientistas frequentemente adotam uma hipótese antes que a série de testes tenha sido considerada minimamente suficiente. Isso é devido à necessidade de adotar-se alguma hipótese para nortear a pesquisa, isto é, a convenção de parar a série de testes pode ocorrer antes mesmo de a série de testes ter começado."

Essa crítica à extrema valorização das convenções resulta de uma forma de naturalismo exibida por Neurath. Para os naturalistas, a ciência, ou o conhecimento, é um fenômeno no mundo, uma parte da natureza, e deve ser estudado como tal. A versão mais famosa do naturalismo é a de Quine que propôs - citando a metáfora do barco de Neurath - que a epistemologia deveria utilizar métodos científicos em seus estudos, deixando de lado as abordagens lógicas como a de Carnap, e tornando-se uma parte da psicologia empírica com elementos da linguística (cf. Quine, 1994 [1969]; Dutra, 2005, cap. 3). A posição de Neurath não é tão radical, já que considera as reconstruções lógico racionais da ciência como algo desejável e importante, de modo que dificilmente Neurath defenderia que a epistemologia devesse restringir-se à psicologia e à linguística, já que contribuições da sociologia, economia, antropologia, e mesmo da lógica, da arte e da filosofia, devem ser levadas em conta na produção do mosaico pluralista da ciência. O próprio Neurath diz, em uma passagem que pode ser vista como a afirmação do naturalismo, que o movimento pela ciência unificada "não propõe uma "superciência' para legislar sobre as ciências especiais", e nem algo "baseado em alguma grande visão metafísica de qualquer tipo". De fato, continua Neurath, “ao invés de buscar-se uma síntese das diferentes ciências sobre a base de uma filosofia primeira e independente, as ciências especiais fornecerão sua própria cola sintetizante" (Neurath, 1983 [1937], p. 172).

7 A pluralidade de métodos na ciência foi apresentada de maneira mais completa por Feyerabend (2007 [1993]). Além de Popper, Feyerabend debate também com Lakatos, que trabalhou no desenvolvimento de um método para justificar racionalmente a ciência (cf. Lakatos, 1968 [1967]). 


\section{A FALTA DE UNIDADE DA GIÊNGIA}

Vimos que a proposta de Neurath para o problema da unidade é que a ciência seja unificada por uma atitude ou orientação, uma maneira de conceber o mundo e de resolver problemas. E, sendo assim, Neurath propõe uma utopia em que todas as pessoas que adotam alguma postura científica em relação ao mundo estabelecem uma cooperação em seus trabalhos e unem-se como uma força política na luta por um mundo melhor. Cabe, então, ao político e engenheiro social propor maneiras de caminhar em direção àquele modelo; o próprio Neurath propôs o “movimento pela ciência unificada”, e a Enciclopédia, como uma dessas maneiras.

Dentre os textos que foram publicados na Enciclopédia, certamente o mais famoso é The structure of scientific revolutions de Thomas Kuhn (1970 [1962]). Essa obra apresentou uma maneira diferente de fazer filosofia da ciência: aquela que lida com problemas que surgem em análises históricas e sociais da prática científica. Foi com base em análises dessa natureza que Kuhn chegou ao seu conhecido modelo de progresso por meio de revoluções científicas.

A partir da década de 1970, estudos como os de Kuhn ganharam espaço na filosofia da ciência, com pesquisas que partem da observação de uma comunidade que pesquisa certo ramo da ciência com o objetivo de encontrar alguma característica saliente. Assim, temas como o problema da demarcação ou o problema da unidade da ciência não são mais centrais na disciplina, bem como questões acerca do conceito de racionalidade da ciência ou do método da ciência. Tais questões passaram a ser discutidas a partir de comunidades científicas e de paradigmas, e as conclusões filosóficas são consideradas sempre em relação ao contexto em que a pesquisa foi feita - o que dá origem ao termo "pesquisa contextualizada", que geralmente designa essa corrente. As pesquisas que atraem mais atenção, dessa forma, não são sobre o padrão de racionalidade na ciência, por exemplo, mas sobre o padrão de racionalidade entre os defensores de certa interpretação da teoria quântica, ou sobre a metodologia adotada em certa comunidade de sociólogos, e não sobre o método científico em geral, ou ainda, sobre como unificar as pesquisas realizadas em biologia evolutiva com aquelas da biologia molecular, ao invés de discutir a unidade da ciência como um todo. E isso não é sem razão, uma vez que os próprios cientistas notam que estudos contextualizados contribuem mais diretamente com o trabalho deles (cf. Feyerand, 2007 [1993]). Não devemos ignorar, todavia, que há trabalhos recentes que procuram encontrar elementos em comum nessa imagem fragmentada da ciência (cf. Cupani, 2013).

Outras linhas de pesquisa da ciência também surgiram, como estudos feministas da ciência, que procuram identificar e analisar a influência do gênero nos resultados e métodos científicos (cf. Haraway, 1996), ou ainda, os estudos sobre a ciência de 
povos não ocidentais, como a medicina chinesa ou a astronomia dos povos pré-colombianos. Assim, expressões como "sociologia da ciência", "historiografia da ciência" e "antropologia da ciência" tornaram-se comuns, seja procurando substituir a filosofia da ciência, seja com o objetivo de constituir-se ao seu lado.

Tais estudos reúnem-se sob a designação mais geral e interdisciplinar de "estudos sobre a ciência" (science studies) (cf. Biagioli, 1999). Podemos descrever tal tradição de pesquisa como pós-moderna, por procurar levar em conta alternativas, ou mesmo críticas, aos parâmetros de racionalidade, objetividade, progresso etc., da ciência que eram tomados como absolutos no período moderno, bem como de valores tradicionais que são tomados como eurocêntricos, etnocêntricos, patriarcais, capitalistas etc., e que surgem no trabalho dos cientistas, principalmente da área de humanidades.

É uma opinião frequente no contexto de tais discussões que a pesquisa contextualizada suplantou a maneira de fazer filosofia da ciência típica do Círculo de Viena. E, de fato, o direcionamento de grande parte da pesquisa em filosofia da ciência mudou. No entanto, geralmente, toma-se como uma ironia o fato de a Estrutura das revoluções científicas de Kuhn ter sido publicada na própria Enciclopédia. Mas ao estudarmos com mais atenção os mosaicos do Círculo de Viena e da Enciclopédia, enfatizando, como sugerimos, as propostas de Neurath, notamos que não há tanta ironia assim. O projeto da Enciclopédia gerou uma linha de pesquisa, discussão e crítica, que mudou a maneira como pesquisadores de todas as áreas veem a ciência. Lembremos, porém, que isso não foi feito pelos textos publicados na Enciclopédia, à exceção da Estrutura, mas pelo esforço de reunir os adeptos da concepção científica de mundo. A utopia que Neurath construía era a de um ambiente intelectual e político que garantisse a liberdade daqueles que pensam de maneira científica, permitindo o avanço de nossa compreensão da ciência. Tal ambiente foi criado e, quando percebemos o papel que a utopia de Neurath teve nisso, notamos que o fracasso da Enciclopédia não foi tão grande quanto julga, por exemplo, Bunge (cf. 2011, p. 147-8).

Ao falarmos da pesquisa contextualizada sobre ciência, não estamos, evidentemente, tratando do ponto de vista de um autor ou de um grupo homogêneo de autores. Como é comum nos pontos de vista chamados pós-modernos, não é possível encontrar grande homogeneidade de opiniões sobre algum assunto. Mas podemos captar alguns traços gerais; utilizando a metáfora de Neurath, podemos ver a imagem gerada pelo mosaico da abordagem contextualizada à filosofia da ciência. Uma visão de tal mosaico pode ser encontrada no "Prefácio à terceira edição" de Contra o método, de Feyerabend. Ele aponta a origem dessa tendência em Kuhn e menciona autores como Pickering, Fine, Putnam, Biagioli, entre outros, e como Dupré, Hacking e Galison, que citaremos abaixo. Tais estudos, diz Feyerabend, "mostram a necessidade de um tratamento do conhecimento científico que seja mais complexo do que aquele que emergi- 
ra do positivismo e de filosofias similares" (Feyerabend, 2007 [1993], p. 13). Na nova linha de pesquisa, ele continua,

o problema não é mais por que e como a 'ciência' muda, mas como se mantém unida. Os filósofos (...) suspeitavam havia já algum tempo que não há apenas uma entidade chamada ciência, com princípios claramente definidos, mas que a ciência compreende grande variedade de abordagens (2007 [1993], p. 13).

Outra visão geral de tal mosaico é apresentada por Alberto Cupani no contexto da discussão sobre a racionalidade da ciência. Ele diz que "a crença de que a ciência é uma atividade eminentemente racional (...) passou de ser uma obviedade para tornarse um assunto polêmico" (Cupani, 2013, p. 15). Ele aponta que pesquisas históricas e sociológicas levantaram dúvidas sobre a racionalidade e sobre outros aspectos tidos como característicos da ciência, como a objetividade e a verdade. Se admitirmos tais dúvidas, diz Cupani, corremos o risco de "ter que aceitar que a ciência é apenas 'um discurso entre outros' acerca da realidade, como prega a mentalidade 'pós-moderna'; que a pretensa 'racionalidade' da ciência é uma miragem devida a nossa inserção na tradição cultural iluminista e positivista" (Cupani, 2013, p. 16). O objetivo de Cupani nesse texto é seguir as argumentações de autores como Ziman, Longino e Kuhn, para dizer que não precisamos abandonar a racionalidade da ciência, apenas buscar outros parâmetros de racionalidade. Ele conclui o texto dizendo que um caminho para isso pode ser a problematização filosófica da chamada tecnociência, o que permitiria distinguir os valores adotados em cada tipo de pesquisa, identificando a racionalidade onde aparece (cf. Cupani, 2013, p. 32-7).

Dissemos que Neurath apresenta uma visão pluralista da ciência como uma concepção de mundo, e propõe um esforço para unificar as diferentes ramificações de tal atitude. Neurath antecipava aquela renovação do tratamento do problema da unidade da ciência que Feyerabend notou. Além disso, a crítica que Neurath faz ao pseudorracionalismo e à tecnocracia, que vimos acima, pode contribuir com o caminho indicado por Cupani.

Ao compreender as propostas de Neurath desse ponto de vista, podemos encontrar uma posição que se afasta da visão tradicional do positivismo, tal como nomeado por Feyerabend e Cupani. Essa afirmação é tema para outros textos. O presente artigo, como explicamos, não tem o objetivo de mostrar como Neurath poderia aproximar-se de Feyerabend; tampouco procuramos discutir o problema da racionalidade científica. O que queremos é apresentar como Neurath lida com o problema da unidade da ciência, e como nessa abordagem pós-moderna mais recente da filosofia da ciência, tal problema é discutido (cf. Galison \& Stump, 1996). 
Galison afirma que "hoje, por todo o mapa disciplinar, chamados para a desunidade da ciência podem ser ouvidos, ecoando através dos campos da ciência e dos science studies" (Galison, 1996a, p. 2). Com isso, ele exprime a tendência geral do volume que ele organiza e introduz, a saber, a tendência de pesquisar para compreender as diferenças entre cada ramo da ciência, as particularidades de cada uma das comunidades científicas, isoladas, com dialetos, visões de mundo e métodos próprios (cf. Stump, 1996). Além de tal orientação de pesquisa ser uma tendência, Dupré aponta que se trata de uma necessidade. Ele nota que existe certo caráter de autoridade atestado pela ciência nessa visão comum, de um sistema único, expressão da racionalidade, da objetividade e da verdade. O adjetivo "científico" acaba sendo usado como um título honorífico, diz Dupré, "a qualquer coisa que satisfaça mesmo os mais magros critérios sociológicos de ser parte da ciência” (Dupré, 1996, p. 115). A solução, continua ele, é mudar a maneira de retratar a ciência: "se a ciência for, ao invés, retratada como uma coleção mista de investigações diversas com apenas relações e interconexões soltas, então recursos particulares à autoridade da ciência devem se sustentar por seus próprios méritos" (p. 115). ${ }^{8}$

Há, então, uma importância política e social em buscar a imagem da ciência como fragmentada, deixando de lado os esforços para unificar toda a ciência e toda a comunidade científica. Como aponta Galison, era importante nos anos 193o que as pessoas se unissem contra o fascismo, o racismo, a segregação social e outras formas de opressão. Mas agora (isto é, pelo menos na época do texto, a década de 1990), os inimigos a serem combatidos mudaram, a ciência deve voltar-se contra as forças de homogeneização política e cultural que tendem a esmagar ideais de multiculturalidade, de autonomia nacional e de liberdade de povos que encontraram uma individualidade. Nas palavras de Galison, “ao invés de guerras mundiais, os conflitos da época pós-guerra têm sido inumeráveis batalhas anti-insurgência, guerras civis, secessões étnicas e movimentos pela autonomia nacional" (1996a, p. 32-3). Assim sendo, não faz mais sentido, de acordo com essa concepção, trabalhar por uma unidade em um mundo que precisa livrar-se de uma tendência à homogenia de ideias, de sistemas político-econômicos etc. A utopia de Neurath ter-se-ia se tornado, segundo Galison, antiquada.

Percebemos justamente a tendência pós-moderna de procurar compreender as diferenças, em oposição à tentativa de classificar e identificar semelhanças. Hacking (1996, pp. 45-53), por exemplo, diz que a estratégia de estabelecer uma metodologia única para a ciência, como Popper e Lakatos procuravam fazer, pode acabar por silen-

8 Esse ponto de vista é o cerne da proposta de Feyerabend (2007 [1993]). A discussão feita por esse autor é bastante abrangente, tendo também a inclinação política que procuramos aqui. Um passo além da situação encontrada por Feyerabend, mas sem deixar de lado o programa do science studies, é indicado em Stump, (1996), que propõe uma releitura das teses da incomensurabilidade. 
ciar formas alternativas de raciocinar. Dessa forma, se cada área da ciência adota um método próprio, uma maneira própria de articular observações e teorias, o que temos é que a humanidade apresentará diversos padrões de raciocínio, o que, sem dúvida alguma, é benéfico.

Como procuramos mostrar, tais características estavam previstas no modelo de ciência de Neurath. A ciência não deve ser retratada como completamente uniforme, como se fosse um sistema, mas em um mosaico composto por peças irregulares; a irregularidade das peças pode mostrar-se na diversidade de métodos e maneiras de pensar adotados por cada um dos ramos da ciência. Vimos, inclusive, que Neurath critica o falseacionismo metodológico da mesma maneira que Hacking viria depois a criticar Popper e Lakatos. A utopia de Neurath não conduz ao desrespeito à soberania de cada nação científica específica, para usar a ilustração de Galison, nem a uma uniformidade de pensamento como Hacking teme. E ainda, o tratamento dado por Neurath ao problema da unidade da ciência permite uma compreensão da ciência como unificada e, ao mesmo tempo, permite a sustentação de uma posição política parecida com aquela defendida por Dupré, já que a postura de Neurath é pluralista, falibilista e aponta na direção de uma educação científica democrática.

Creath, de sua parte, argumenta que é errônea a suposição de que o conceito de ciência fragmentada que aparece na pesquisa contextualizada seja absolutamente contrário à concepção de ciência unificada que aparece no Círculo de Viena e na Enciclopédia. Em suas palavras, “aquilo que nossos predecessores vienenses estavam realmente defendendo é muito mais são e sensível do que tem sido suposto" (Creath, 1996, p. 158). A referência de Greath é a uma proposta de Galison, na qual este aponta que uma maneira de pensar a ciência em uma unidade é a que considera aspectos em comum na experiência desenvolvida em simulações computacionais; o mundo de que trata a ciência é cada vez mais um mundo construído em tais simulações. E, então, diz Galison, pouco a pouco, "o computador representa não mais uma ferramenta, mas a própria natureza" (1996b, p. 157). E áreas de pesquisa outrora isoladas "foram conectadas por estratégias práticas, que tinham sido anteriormente separadas devido aos seus objetos de investigação" (p. 157). Devido a limitações de espaço no presente texto, não vamos discutir a proposta de Galison em detalhe; basta entendermos que ele está propondo que a estratégia de pesquisar usando simulações computacionais tem promovido uma unificação social entre ramos distintos da ciência. Creath nota, então, que, apesar de Galison (cf. 1996b, p. 118-9) declarar-se contra certos aspectos da ciência unificada do Círculo de Viena, "essa é a visão de unidade-como-cooperação que era defendida por Neurath" (Creath, 1996, p. 169).

Deve ficar claro que, como Creath, não estamos defendendo que haja uma grande e absoluta semelhança entre tudo o que Neurath diz e tudo o que propõem os pós- 
modernos da filosofia da ciência. O que queremos é apenas notar alguns pontos de afinidade para preparar o caminho para novos desenvolvimentos, para tentar recuperar as propostas de Neurath em discussões atuais de filosofia da ciência. Um desses desenvolvimentos é aquele traçado por Creath, de confrontar a ciência unificada de Neurath com a construção do mundo como simulação computadorizada de Galison. Outro desses caminhos é o de pensar qual problema da sociedade poderia ser tratado com uma mudança em nossa concepção de ciência.

\section{Considerações FinAis: A ATUALIdAdE DA UTOPiA}

Apresentamos neste artigo a visão de Neurath da ciência unificada como uma atitude em relação ao mundo. Tal visão é humanista, pois a atitude científica, que é aquilo que unifica a ciência, é um direcionamento em relação aos problemas do mundo que considera, nas palavras do Manifesto, que "tudo é acessível aos seres humanos; e o ser humano é a medida de todas as coisas" (Hahn, Neurath \& Carnap, 1979 [1929], p. 87). Utilizando as figuras de linguagem de tal texto, não há "enigmas indecifráveis", "profundezas insondáveis" ou "distâncias escuras". Os poderes humanos, contudo, não são absolutos, já que Neurath vê o conhecimento como um fenômeno natural, construído de maneira falível, nunca como um sistema perfeito. Para utilizar, mais uma vez, a metáfora do barco de Neurath, cabe apenas aos seres humanos reconstruir o barco, e este é um empreendimento alcançável. Mas não podemos atracar para fazer a reforma da melhor maneira que conseguirmos imaginar, temos que seguir navegando em mar aberto.

Vimos também que Neurath propôs uma utopia para perseguir tal objetivo, a saber, o movimento pela ciência unificada, que deu origem à Enciclopédia. Tal projeto aproximaria e fortaleceria pessoas do mundo todo que adotam a atitude científica em suas vidas e em seus trabalhos. A utopia de Neurath era a de que haveria comunicação ampla e livre entre todas essas pessoas, possibilitando, além do intercâmbio de práticas científicas, o estabelecimento de uma força política. A obra resultante de tal projeto, a própria Enciclopédia, seria um mosaico composto por peças irregulares e diferentes umas das outras, mas formando uma imagem pluralista da atitude científica de uma época. Mas como não é possível atracar em uma doca seca para realizar tal utopia de maneira ideal, o projeto teve seus problemas.

Falamos neste texto, ainda, da abordagem pós-moderna aos estudos da ciência, que parece ter substituído a abordagem do Círculo de Viena na filosofia da ciência. E pudemos encontrar um ponto de acordo entre a orientação contextualizada de pesquisa e as propostas de Neurath. Os estudos resultantes da abordagem pós-moderna 
fortalecem a imagem pluralista do mosaico, ao considerar que cada comunidade científica tem suas particularidades. O que percebemos de diferente é o direcionamento político. Por um lado, Neurath enfatiza que devemos notar as semelhanças de atitude em meio a toda a diversidade da ciência para criar uma força política e social contra o obscurantismo; por outro lado, os defensores da abordagem contextualizada defendem que devemos compreender as diferenças e particularidades de cada uma das variações da atitude científica, para evitar uma homogeneização e massificação do conhecimento humano.

Embora se encontrem muitas diferenças entre as propostas de Neurath e dos praticantes da pesquisa contextualizada, podemos notar que o tratamento dado por ele ao problema da unidade da ciência não é incompatível com os objetivos da desunidade da ciência proposta por defensores da pesquisa contextualizada. Há, entretanto, um desafio sério que o ponto de vista contextualista apresenta a alguém que se aventure a pensar nesses termos que estamos propondo. Trata-se da questão sobre a atualidade da utopia de Neurath: faria sentido sustentar nos dias de hoje essa utopia? Tendo em vista que nossa situação social, política e econômica é bastante diferente daquela encontrada no período entre guerras, quando a Enciclopédia foi proposta, deveria haver mudanças no programa. E a resposta da abordagem pós-moderna, de que a desunidade da ciência é a solução, também parece já não fazer mais muito sentido. A tendência de homogeneização social, contra a qual os pós-modernos lutavam, parece ter ficado para trás com o fim da guerra fria, do mesmo modo que o totalitarismo de maneira geral deixou de assombrar-nos no final da Segunda Guerra Mundial. Contudo, é amplamente discutível se o totalitarismo - e o obscurantismo que arma essa forma de governo - deixou de ser uma ameaça social, bem como se não há mais as tendências homogeneizantes no mundo atual. O que podemos notar claramente é que esses problemas parecem ter perdido a exclusividade no posto de maiores inimigos da ciência e da filosofia.

Temos, assim, a questão sobre qual problema do mundo atual poderia ser combatido com uma utopia sobre a ciência. E, diante disso, fica ainda a questão de qual imagem da ciência poderia alimentar tal utopia. Responder a essa questão está além das possibilidades do presente artigo, mas podemos rascunhar aqui uma indicação.

$\mathrm{Na}$ Introdução, mencionamos a concepção pragmatista que considera a ciência como um produto fisiológico humano resultante da evolução da espécie. O que não dissemos é que existe um parentesco entre essa proposta e o conceito de ciência proposto pelo Círculo de Viena. Tal parentesco foi estabelecido na elaboração da Enciclopédia. Apontamos que Charles Morris era um dos editores daquela obra, mas a presença pragmatista mais ilustre é a de Dewey, que escreveu um capítulo no número de abertura da Enciclopédia, ao lado de Neurath, Carnap, Morris, Russell e Bohr, e também con- 
tribuiu com um número sobre axiologia (cf. Dewey, 1970 [1939]). Assim, o mosaico da Enciclopédia nos mostra uma ligação entre o projeto vienense e a escola filosófica americana. E nessa ligação podemos encontrar algumas indicações sobre a atualidade da utopia em questão.

Em seu capítulo, Dewey nota que a ciência é ensinada de maneira inadequada. Na educação básica, diz Dewey, ensina-se pouca ciência e, quando se faz, não é como uma atitude, mas como um corpo de conteúdos. O que acontece é que as crianças não têm um contato adequado com a ciência na idade em que são mais curiosas, em que têm mais tendência ao comportamento experimental. Os jovens acabam vendo a atitude científica como algo estranho, com o qual eles não tiveram contato ao longo da vida. A ciência, assim, parece inacessível à maioria das pessoas. Dewey nota ainda que na educação superior é dada grande ênfase à formação profissional, o que ele não considera ruim, mas que seria melhor se em tal formação fosse cultivada a maneira científica de pensar e de resolver problemas. A educação técnica, diz Dewey, deveria ser voltada ao objetivo liberal de desenvolver a atitude científica para o melhoramento da

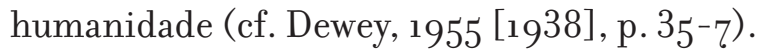

Os comentários de Dewey fazem referência à educação nos Estados Unidos no final da década de 1930. Mas não podemos deixar de notar que há semelhanças com a situação educacional atual no nosso país, embora seja necessário um estudo mais aprofundado para afirmar isso. Se a Enciclopédia teve sucesso na construção de uma comunidade que discute e faz ciência, precisamos reconhecer que tal empreendimento fracassou no objetivo de tornar a ciência mais presente na sociedade e na vida humana como um todo, pelo menos essa concepção da ciência como uma atitude. Talvez a principal causa disso tenha sido o fato de Dewey ter se afastado do projeto enciclopedista devido a intrigas e mal-entendidos, principalmente após a morte de Neurath (cf. Reisch, 2005; Cunha, 2012).

A filosofia da ciência atualmente produz na maioria das vezes retratos da ciência como algo fragmentado em comunidades que não se comunicam entre si, em disciplinas que não se conectam. Retratos da fragmentação da ciência são muito importantes, justamente por contribuírem diretamente com as pesquisas científicas propriamente ditas, e por ajudarem a evitar o uso inadequado da ciência em argumentos por recurso à autoridade. Mas a sociedade só teria a ganhar com mais retratos filosóficos que enfatizam a unidade da ciência. A diferença seria sentida principalmente em uma educação voltada ao ensino de uma maneira de pensar ou de uma maneira de conceber o mundo.A

Agradecimentos. O autor é pesquisador de pós-doutorado na UFSC com bolsa do CNPq. Realiza pesquisa no Núcleo de Epistemologia e Lógica do Departamento de Filosofia de tal instituição com supervisão do professor Luiz Henrique Dutra. 
Ivan FERREIRA DA Gunha

Departamento de Filosofia,

Centro de Filosofia e Ciências Humanas,

Universidade Federal de Santa Catarina,

Florianópolis, Brasil.

clockwork.ivan@gmail.com

\title{
A discussion about the unity of science: Neurath and the utopia of unified science
}

\begin{abstract}
This paper discusses Otto Neurath's proposal for the problem of the unity of science. This author, a wellknown member of the Vienna Circle, proposes that science is to be unified by the so-called scientific world-conception (wissenschaftliche Weltauffassung), a characteristic orientation or attitude of science towards the world and the problems it deals with. In this paper, emphasis is given to the social aspect of Neurath's projects, as found, for instance, in the International Encyclopedia of Unified Science. It contrasts Neurath's proposal with the post-modernist criticism, developed in the contextualized approach to science studies, that stems from studies of scientific communities and, in general, presents the conclusion that there is no unifying factor for science. The term 'science' would then denote just a collection of activities with no relevant common characteristics. The comparison made shows that Neurath's position is compatible with the contextualized approach, even though he defends the unity of science. Finally, the political aspect of Neurath's proposal is evaluated in the light of the post-modernist criticism, and it is pointed out that the ideas of the Vienna Circle and the Encyclopedia might be valuable nowadays.
\end{abstract}

KEYwords • Unity of science. Neurath. Vienna Circle. Contextualized approach. Utopia.

Unified science.

\section{REFERÊNGIAS BIBLIOGRÁFIGAS}

Biagioli, M. (Ed.). The science studies reader. New York: Routledge, 1999.

BlAGK, M. (Ed.). Keytexts. Bristol: Thoemmes, 1995.

Bunge, M. Two unification strategies: analysis or reduction, and synthesis or integration. In: Symons,

J.; Ромво, O. \& Torres, J. M. (Ed.). Otto Neurath and the unity of science. New York: Springer, 2011. p. $145-57$.

Carnap, R. Überwindung der Metaphysik durch logische Analyse der Sprache. Erkenntnis, 2, 1, p. 219-41, 1931.

. Testability and meaning. Philosophy of Science, 3, p. 420-71, 1936.

Testability and meaning. Philosophy of Science, 4, p. 1-4,0, 1937 .

The unity of science. In: Black, M. (Ed.). Key texts. Bristol: Thoemmes, 1995 [1931].

The logical syntax of language. Translation A. Smeaton. Chicago/La Salle: Open Court, 2002 [1934].

The logical structure of the world and pseudoproblems in philosophy. Translation R. George. Chicago/La

Salle: Open Court, 2003 [1928]. 
CARnap, R. The logical structure of the world. In: . The logical structure of the world and pseudoproblems in philosophy. Translation R. George. Chicago/La Salle: Open Court, 2003 [1928]. p. 1-3oo.

CARTWRIght, N. et al. Otto Neurath: philosophy between science and politics. Cambridge: Cambridge University Press, 1996.

Cat, J.; Cartwright, N. \& Chang, H. Otto Neurath: politics and the unity of science. In: Galison, P. \& Stump, D. (Ed.). The disunity of science. Stanford: Stanford University Press, 1996. p. 347-69.

Cohen, R. \& Neurath, M. (Ed.). Philosophical papers of Otto Neurath, 1913-1946. Dordrecht: Reidel, 1983.

Creath, R. The unity of science: Carnap, Neurath and beyond. In: Galison, P. \& Stump, D. (Ed.). The disunity of science. Stanford: Stanford University Press, 1996. p. 158-69.

Cunha, I. F. Values and logical tolerance: John Dewey and Rudolf Carnap. Cognitio-Estudos, 7, 1, p. 9-18, 2010.

. John Dewey and the logical empiricist unity of science. Cognitio, 13, 2, p. 219-30, 2012.

Cupani, A. O que aconteceu com a racionalidade da ciência? In: Dutra, L. H. \& Pessoa Júnior, O. (Ed.). Racionalidade e objetividade científicas. Florianópolis: NEL/UFSG, 2013. p. 15-411.

Dewey, J. Unity of science as a social problem. In: Neurath, O.; Garnap, R. \& Morris, G. (Ed.). International encyclopedia of unified science. Chicago: The University of Chicago Press, 1955 [1938]. v. 1, p. 29-38. . Theory of valuation. In: Neurath, O.; Garnap, R. \& Morris, G. (Ed.). Foundations of the unity of science - toward an international encyclopedia of unified science. Chicago: The University of Chicago Press, 1970 [1939].v. 2, p. 379-447.

. Logic: the theory of inquiry. Carbondale: Southern Illinois University Press, 2008 [1938].

Dupré, J. Metaphysical disorder and scientific disunity. In: Galison, P. \& Stump, D. (Ed.). The disunity of science. Stanford: Stanford University Press, 1996. p. 101-17.

Dutra, L. H. Oposições filosóficas. Florianópolis: Editora da UFSC, 2005.

Dutra, L. H. \& Mortari, G. (Ed.).Anais do VSimpósio Internacional Principia. Florianópolis: NEL/UFSC, 2009. p. 53-67. (Rumos da Epistemologia, 9).

Dutra, L. H. \& Pessoa Júnior, O. (Ed.). Racionalidade e objetividade científicas. Florianópolis: NEL/UFSC, 2013. (Rumos da Epistemologia, 12).

Feyerabend, P. Contra o método. Tradução C. Mortari. São Paulo: Editora Unesp, 2007 [1993].

Friedman, M. A parting of the ways - Carnap, Cassirer, and Heidegger. Chicago/La Salle: Open Court, 2000.

Friedman, M. \& Creath, R. (Ed.). The Cambridge companion to Carnap. Cambridge: Cambridge University Press, 2007 .

Galison, P. Introduction: the context of disunity. In: Galison, P. \& Stump, D. (Ed.). The disunity of science. Stanford: Stanford University Press, 1996a. p. 1-33.

. Computer simulations and the trading zone. In: Galison, P. \& Stump, D. (Ed.). The disunity of science. Stanford: Stanford University Press, 1996b. p. 118-57.

Galison, P. \& Stump, D. (Ed.). The disunity of science. Stanford: Stanford University Press, 1996.

Hacking, I. The disunities of the sciences. In: Galison, P. \& Stump, D. (Ed.). The disunity of science. Stanford: Stanford University Press, 1996. p. 37-74.

Hahn, H.; Neurath, O. \& Carnap, R. Wissenschaftliche Weltauffassung: der Wiener Kreis. In: Hegselmann, R. (Ed.). Otto Neurath, Wissenschaftliche Weltauffassung, Sozialismus und logischer Empirismus. Frankfurt am Main: Suhrkamp Verlag, 1979 [1929]. p. 81-101.

Haraway, D. Modest witness: feminist diffractions in science studies. In: Galison, P. \& Stump, D. (Ed.). The disunity of science. Stanford: Stanford University Press, 1996. p. 428-41.

Hegselmann, R. (Ed.). Otto Neurath, Wissenschaftliche Weltauffassung, Sozialismus und logischer Empirismus. Frankfurt am Main: Suhrkamp Verlag, 1979.

Kornblith, H. (Ed.). Naturalizing epistemology. 2. ed. Cambridge: The MIT Press, 1994. 
Kunn, T. The structure of scientific revolutions - enlarged. In: Neurath, O.; Garnap, R. \& Morris, G. (Ed.). Foundations of the unity of science-toward an international encyclopedia of unified science. Chicago: The University of Chicago Press, 1970 [1962]. v. 2, p. 53-272.

LAKaTOs, I. The problem of inductive logic-studies in logic and the foundations of mathematics. Amsterdam: North-Holland Publishing Company, 1968.

. Changes in the problem of inductive logic. In: The problem of inductive logic - studies in logic and the foundations of mathematics. Amsterdam: North-Holland Publishing Company, 1968 [1967].

Liston, G. O fisicalismo de Neurath e os limites do empirismo. In: Dutra, L. H. \& Mortari, C. (Ed.). Anais do V Simpósio Internacional Principia. Florianópolis: NEL/UFSG, 2009· p. $5^{3-67}$.

Nemeth, E. Otto Neurath's utopias. The will to hope. Translation T. Uebel. In: UebeL, T. (Ed.). Rediscovering the forgotten Vienna Circle - Austrian studies on Otto Neurath and the Vienna Circle. Dordrecht/Boston/ London: Kluwer, 1991 [1982]. p. 285-92.

Freeing up one's point of view: Neurath's machian heritage compared with Schumpeter's. In: Nemeth, E.; Schmitz, S. \& Uebel, T. (Ed.). Otto Neurath's economics in context. New York: Springer, 2007. p. 13-36.

Nemeth, E.; Schmitz, S. \& Uebel, T. (Ed.). Otto Neurath's economics in context. New York: Springer, 2007.

Nemeth, E. \& Stadler, F. (Ed.). Encyclopedia and utopia - the life and work of Otto Neurath. Dordrecht: Kluwer, 1996.

Neurath, M. \& Cohen, R. Memories of Otto Neurath. In: Cohen, R. \& Neurath, M. (Ed.).Empiricism and sociology. Dordrecht: Reidel, 1973. p. 1-83.

Neurath, O. Unified science as encyclopedic integration. In: Neurath, O.; Carnap, R. \& Morris, G. (Ed.). International encyclopedia of unified science. Chicago: The University of Chicago Press, 1955 [1938]. v.1, p. 1-27.

.Anti-Spengler. Translation M. Neurath \& P. Foulkes. In: Cohen, R. \& Neurath, M. (Ed.). Empiricism and sociology. Dordrecht: Reidel, $197^{3}$ [1921]. p. 158-213.

. Protocol statements. Translation R. Cohen \& M. Neurath. In: Cohen, R. \& Neurath, M. (Ed.). Philosophical papers of Otto Neurath, 1913-1946. Dordrecht: Reidel, 1983 [1932-1933]. p. 91-9.

. Pseudorationalism of falsification. Translation R. Cohen \& M. Neurath. In: Cohen, R. \& Neurath, M. (Ed.). Philosophical papers of Otto Neurath, 1913-1946. Dordrecht: Reidel, 1983 [1935]. p. 121-31.

. Encyclopedia as “model”. Translation R. Bouvier. In: Conen, R. \& Neurath, M. (Ed.). Philosophical papers of Otto Neurath, 1913-1946. Dordrecht: Reidel, 1983 [1936]. p. 145-58.

Unified science and its encyclopedia. In: Cohen, R. \& Neurath, M. (Ed.). Philosophical papers of Otto Neurath, 1913-1946. Dordrecht: Reidel, 1983 [1937]. p. 172-82.

. Universal jargon and terminology. In: Cohen, R. \& Neurath, M. (Ed.). Philosophical papers of Otto Neurath, 1913-1946. Dordrecht: Reidel, 1983 [1941]. p. 213-29.

The orchestration of the sciences by the encyclopedism of logical empiricism. In: CoHen, R. \& Neurath, M. (Ed.). Philosophical papers of Otto Neurath, 1913-1946. Dordrecht: Reidel, 1983 [1946]. p. $230-42$.

Neurath, O.; Bohr, N.; Dewey, J.; Russell, B.; Carnap, R., \& Morris, C. Encyclopedia and unified science. In: Neurath, O.; Garnap, R. \& Morris, G. (Ed.). International encyclopedia of unified science. Chicago: The University of Chicago Press, 1955 [1938]. v.1, p. 1-76.

Neurath, O.; Carnap, R. \& Morris, C. (Ed.). International encyclopedia of unified science. Chicago: The University of Chicago Press, 1955. v. 1.

$\&$ __. (Ed.). Foundations of the unity of science-toward an international encyclopedia of unified science. Chicago: The University of Chicago Press, 1970. v. 2.

Neurath, P. Otto Neurath: life and work. In: Nemeth, E. \& Stadler, F. (Ed.). Encyclopedia and utopia - the life and work of Otto Neurath. Dordrecht: Kluwer, 1996. p. 15-28. 
Popper, K. A lógica da pesquisa científica. 10. ed.Tradução L. Hegenberg \& O. S. Motta. São Paulo: Cultrix, 2003 [1934].

Quine, W. van O. Epistemology naturalized. In: Konnblith, H. (Ed.). Naturalizing epistemology. 2 ed. Cambridge: The MIT Press, 1994 [1969].p. 15-31.

Reisch, G. How the cold war transformed philosophy of sdcience. Cambridge: Cambridge University Press, 2005 .

Ricketts, T. Tolerance and logicism: logical syntax and the philosophy of mathematics. In: Friedman, M. \& Creath, R. (Ed.). The Cambridge companion to Carnap. Cambridge: Cambridge University Press, 2007. p. 200-25.

Stump, D. Afterword: new directions in the philosophy of science studies. In: Galison, P. \& Stump, D. (Ed.). The disunity of science. Stanford: Stanford University Press, 1996. p. 443-50.

Symons, J.; Ромво, O. \& Torres, J. M. (Ed.). Otto Neurath and the unity of science. New York: Springer, 2011.

Uebel, T. (Ed.). Rediscovering the forgotten Vienna Circle - Austrian studies on Otto Neurath and the Vienna Circle. Dordrecht: Kluwer, 1991. 